SCIENTIFIC LETTER

\title{
Incidence and factors influencing left atrial clot in patients with mitral stenosis and normal sinus rhythm
}

\author{
S J Saidi, M H K Motamedi
}

Heart 2004;90:1342-1343. doi: 10.1136/hrt.2003.024315

M itral stenosis (MS) is a common finding in rheumatic heart disease and can lead to enlargement of the left atrium and stasis of blood in this heart chamber. This can lead to an increased risk of clot formation in the left atrium and the left atrial appendage.

In numerous studies to date, various precipitating factors for the formation of a clot inside the left atrium have been identified, including atrial fibrillation (AF) rhythm, left atrial size, duration of symptoms, advanced age, and severity of MS. Furthermore, mitral regurgitation (MR) in conjunction with MS has been mentioned as a factor which reduces the risk of left atrial clot formation. ${ }^{1-3}$

This study was performed to determine the incidence of left atrial clot in a group of patients who remained in normal sinus rhythm (NSR) and to establish the factors which play a determining role in this process.

\section{METHODS}

In this descriptive, analytical study, 203 patients with MS, who presented to our department for percutaneous mitral valvuloplasty or mitral valve surgery from January 2001 to February 2002, were studied. All patients underwent transthoracic and transoesophageal echocardiography and the results were recorded and analysed.

\section{RESULTS}

Forty three patients (21.3\%) were male. Median age was 44.8 (12.3) years. Of the patients studied, 88 patients $(43.4 \%)$ had pure MS, 47 patients $(23.2 \%)$ had MS plus MR, and 68 patients $(33.5 \%)$ had MS associated with other valvar abnormalities. One hundred and seven of the total number of patients $(52.7 \%)$ had NSR and 96 patients $(47.3 \%)$ had AF. In the patients with NSR, 14 patients (13.5\%, group A) had a clot in the left atrium and the remainder (group B) had no clot. The median age of group A patients was 38.7 (9.5) years, and $41.3(12.2)$ years in group $B(p=0.458)$. The average mitral valve score was 8.3 (1.9) in group A and 7.9 (1.5) in group $B$; the difference was not significant $(p=0.431)$. The prevalence of left atrial clot in the AF group was 26.1\% (23 patients), and $13.5 \%$ (14 patients) in the NSR group; this difference was significant $(\mathrm{p}=0.02)$.

From the group of MS patients in NSR, $22(20.8 \%)$ were male and the mean age was 41 (11.8) years old. From this group, 14 patients (13.5\%) had left atrial clot. Demographic and echocardiographic variables in the NSR group are depicted in table 1 .

As depicted in table 2, left atrial clot was present in 23 patients $(26.1 \%)$ in the AF group and 14 patients $(13.5 \%)$ in the NSR group, the difference being significant $\left(\chi^{2}\right.$, $\mathrm{p}=0.02$ ).

In MS patients in NSR, mean mitral valve surface area was $1.2(0.9) \mathrm{cm}^{2}$ while this value was $1.1(0.4) \mathrm{cm}^{2}$ in the AF group; the difference was not significant ( $t$ test, $\mathrm{p}=0.251$ ).

In MS patients in NSR, smoke pattern in the left atrium was seen in 63 patients $(62.4 \%)$, while this pattern was seen
Table 1 Demographic and echocardiographic findings in the MS patients with and without left atrial clot

\begin{tabular}{llll}
\hline & \multicolumn{3}{l}{ MS in NSR } \\
\cline { 2 - 4 } & $\begin{array}{l}\text { With clot } \\
(\mathbf{n = 1 4 )}\end{array}$ & $\begin{array}{l}\text { Without clot } \\
(\mathbf{n}=93)\end{array}$ & $\mathbf{p}$ Value \\
\hline Male (\%) & 21.4 & 21.3 & 0.616 \\
Age & $38.7(9.5)$ & $41.3(12.2)$ & 0.458 \\
Left atrial size & $4.7(0.6)$ & $4.7(0.7)$ & 0.803 \\
Mitral score & $8.3(1.9)$ & $7.9(1.5)$ & 0.431 \\
Valve gradient & $10.0(3.09)$ & $10.0(4.1)$ & 0.595 \\
Mitral surface area & $1.02(0.2)$ & $1.2(1.0)$ & 0.423 \\
\hline & & & \\
\hline
\end{tabular}

Table 2 Demographic and echocardiographic findings with respect to type of heart rhythm in patients with MS

\begin{tabular}{lllr}
\hline & NSR $(\mathbf{n = 1 0 7 )}$ & AF $(\mathbf{n = 9 6 )}$ & p Value \\
\hline Male (\%) & 20.8 & 21.9 & 0.491 \\
Age & $41.03(11.8)$ & $49.02(11.3)$ & $<0.001$ \\
Left atrial size & $4.7(0.7)$ & $5.2(0.9)$ & $<0.001$ \\
Mitral score & $7.9(1.6)$ & $8.6(1.5)$ & 0.009 \\
Prevalence of left atrial clot & & & 0.02 \\
(\%) & 13.5 & 26.1 & \\
Spontaneous echo contrast & & & $<0.001$ \\
(\% smoke) & 62.4 & 89.5 & \\
Mitral surface area & $1.2(0.9)$ & $1.1(0.4)$ & 0.251 \\
\hline
\end{tabular}

in 77 patients $(89.5 \%)$ in the AF group; the difference was significant $(\mathrm{p}<0.001)$.

The size of the left atrium was $4.7(0.7) \mathrm{cm}$ in the NSR group and $5.2(0.9) \mathrm{cm}$ in the AF group; the difference was significant $(\mathrm{p}<0.001)$. Concerning the variables of age and valve gradient, the difference between the two groups was significant (table 2 ).

The hypothesis that coexistence of MR with MS reduces the chances of left atrial clot formation was tested in this study. In the pure MS patients in NSR, seven patients (14.3\%) had a clot whereas in the MS plus MR patients in NSR, three patients $(11.5 \%)$ revealed clot formation in the left atrium. Although the results revealed less clot in the combined MS and MR group, the difference was not significant $\left(\chi^{2}, \mathrm{p}=0.521\right)$.

\section{DISCUSSION}

Risk factors for clot formation in MS patients in NSR were evaluated in this study. As mentioned earlier, mitral valve surface area did not reveal a significant relation to clot formation. However, this issue is quite controversial, as a

Abbreviations: MR, mitral regurgitation; MS, mitral stenosis; NSR, normal sinus rhythm 
study from Spain in 2000 revealed a significant relation between small mitral valve surface area and clot formation, with an odds ratio of $0.17 .{ }^{4}$ This issue has been supported by other studies and it has even been emphasised that in multivariate analysis, the only independent predictor for left atrial clot formation is mitral valve area. ${ }^{3}$ Despite these reports, another study has shown no significant relation between mitral valve area and mean valve gradient, and clot formation. ${ }^{15}$

In our study, no meaningful relation was found between left atrial size and the presence of a clot in the left atrium, or between age and clot formation. On the other hand, despite the fact that the mean mitral valve score in the MS group in NSR with a clot was higher than the group without a clot, the difference was not significant.

In a study in China, the presence of a left atrial clot in MS patients with small valve area, large valve gradients, and no MR revealed a moderate to strong statistical relation, but did not reveal a relation to left atrial size. ${ }^{2}$ In other reports, however, left atrial size and age were shown to be related to the presence of a clot. ${ }^{136}$

Another result of this study was the comparison of clot frequency in patients in NSR with those in AF rhythm. Clotting was more common in the AF group, with the difference being significant, as could be expected. Other studies have also revealed the significant effect of AF rhythm on left atrial clot formation. ${ }^{1-7}$ Age of the patients in AF rhythm in our study was significantly higher than the group in NSR.

Concerning the left atrial size, mitral valve score and valve gradient, obtained values were significantly higher in the AF group compared to the group in NSR. Also concerning the coexistence of MR with MS and its effect on inhibiting clot formation, our study showed a lower percentage of clotting in the combined pathology (MS and MR) group compared to the pure MS group, although the difference was not significant. This could be because the MR present in the majority of the patients in this study was of mild severity.

Despite the fact that left atrial clot is usually sought in MS patients with AF rhythm, MS patients in NSR are also at risk from intra-atrial clot formation. Although this risk is less than the AF rhythm group, it is sufficient to warrant measures for prevention of thromboembolic episodes in this group of patients.

\section{Authors' affiliations}

S J Saidi, Department of Cardiology, Baqiatallah University of Medical Sciences, Tehran, Iran

M H K Motamedi, Department of Cardiovascular Surgery, Baqiatallah University of Medical Sciences, Tehran, Iran

Correspondence to: Dr S Jalal Saidi, 254, Entrance 8, Block-E1, Phase 3, Shahrak Ekbatan, Tehran, Iran; saidi39@yahoo.com

Accepted 12 January 2004

\section{REFERENCES}

1 Gaswami KC, Yadav R, Rao MB, et al. Clinical and echocardiographic predictors of left atrial clot and spontaneous echo contrast in patients with severe rheumatic mitral stenosis: a prospective study in 200 patients by transesophageal echocardiography. Int J Cardiol 2000;73:273-9.

2 Li YH, Hwag JJ, Ko YL, et al. Left atrial spontaneous echo contrast in patients with rheumatic mitral valve disease in sinus rhythm: Implication of an altered left atrial appendage function in its formation. Chest 1995; 108:99-103.
3 Agarwal AK, Venugopalan P. Left atrial spontaneous echo contrast in patients with rheumatic mitral valve stenosis in sinus rhythm: relationship to mitral valve and atrial measurements. Int J Cardiol 2001;77:63-8.

4 Gonzalez-Torrecilla E, Garcia-Fernandez MA, Ferez-David E, et al. Predictors of left atrial spontaneous echo contrast and thrombi in patients with mitral stenosis and atrial fibrillation. Am J Cardiol 2000;86:529-34.

5 Ha JW, Chund N, Kang SM, et al. Enhanced detection of atrial spontaneous echo contrast by transthoracic harmonic imaging in mitral stenosis. J Am Soc Echocardiogr 2000;13:849-54

6 Acarturk, Usal A, Demir M, et al. Thromboembolism risk in patients with mitral stenosis. Jpn Heart J 1997;38:669-75.

7 Bernstein NE, Demopoulous LA, Tunick PA, et al. Correlates of spontaneous echo contrast in patients with mitral stenosis and normal sinus rhythm. Am Heart J 1994; 128:287-92.

\section{WEB TOP 10}

www.heartinl.com

These articles scored the most hits on Heart's website during August 2004

1 Will oral antithrombin agents replace warfarin?

PR Sinnaeve, FJ Van de Werf

August 2004;90:827-8. (Editorials)

2 Management of dyslipidaemia

GR Thompson

August 2004;90:949-55. (Education in Heart)

3 Management of acute coronary syndromes: an update KAA Fox

June 2004;90:698-706. (Education in Heart)

4 Joint British recommendations on prevention of coronary heart disease in clinical practice

December 1998;80:1-29.

5 Management and follow up of prosthetic heart valves C Seiler July 2004;90:818-24. (Education in Heart)

6 B type natriuretic peptide testing: where are we now? MR Cowie

July 2004;90:725-6. (Editorial)

7 Role of oral anticoagulation in management of atrial fibrillation

E Crystal, SJ Connolly

July 2004;90:813-7. (Education in Heart)

8 Anaemia and heart failure

AJS Coats

September 2004;90:977-9. (Editorial)

9 British Cardiac Society Working Group on the definition of myocardial infarction

KAA Fox, J Birkhead, R Wilcox, C Knight, J Barth

June 2004;90:603-9.

10 Risk stratification in acute coronary syndrome: focus on unstable angina/non-ST segment elevation myocardial infarction

$R$ Bugiardini

July 2004;90:729-31. (Editorial)

Visit the Heart website for hyperlinks to these articles, by clicking on "Top 10 papers"

www.heartinl.com 